\title{
The Impact of Healthy Human Capital on the Labor Participation of Chinese Elderly
}

\author{
Zhang Youlu ${ }^{1, a}$, Chi Ying ${ }^{2, b^{*}}$ \\ ${ }^{1}$ School of Economics and Management, Beijing Jiaotong University, Beijing 100044, China \\ ${ }^{2}$ School of Economics and Management, Beijing Jiaotong University, Beijing 100044, China
}

\begin{abstract}
The labor participation of the elderly is an important level of labor supply in China, and healthy human capital is one of the main factors affecting the labor participation of the elderly. Based on the data of the Chinese Longitudinal Healthy Longevity Survey (CLHLS) in 2014, this paper uses the Probit model to empirically analyze the impact of the healthy human capital of the elderly in China on their labor force participation rate. The results show that when individual characteristic variables, family characteristic variables and social characteristic variables are added, healthy human capital is positively correlated with labor participation of retired elderly people. The better health status is, the higher labor participation rate is. With the decline in health status, the labor force participation rate of retired elderly people decreased significantly. The influence of healthy human capital on labor participation of the elderly in China is also heterogeneous between urban and rural areas, gender and age, among which the influence of healthy human capital on labor participation of the elderly in rural areas, males and young age groups is higher than that in urban areas, females and elderly retirees.
\end{abstract}

\section{Introduction}

With the development of economy and society, the life expectancy of human beings keeps increasing and the birth rate keeps falling, the population structure has undergone a great transformation and faces the problem of aging in an inverted pyramid. At present, the problem of population aging in the world is becoming more and more prominent, which has attracted extensive attention from the international community. China has entered a deeply aging society. In 2018, 249 million people were 60 years old or above, accounting for $17.9 \%$ of the total population. Among them, 167 million were 65 years old or above, accounting for $11.9 \%$ of the total population, 3.1 percentage points higher than in 2010. By 2050, China's population over 60 will exceed $1 / 3$, and the population over 65 will reach $25 \%$, making China the most aging country in the World (World Bank, 2018). In general, the direct impact of the aging population is mainly reflected in two aspects: first, the health problem of the elderly population. The aging population leads to a sharp increase in the dependency ratio of the elderly. Second, the problem of labor supply. The aging of the population leads to a decline in the size and proportion of the working-age population, the traditional demographic dividend gradually disappears, and the quantity of labor supply gradually decreases, which may lead to the problem of labor shortage in the future.
To deal with an ageing population of the elderly population health and labor shortages, vigorously develop old human resources has become the consensus of the world, by encouraging the elderly labor supply behavior, protect the rights of labor participation in the elderly, young elderly resources will effectively improve the development of the Chinese labor participation rate, improving the structure of the labor supply, alleviate the contradiction of labor supply. For the elderly, healthy human capital is the most important factor affecting their labor supply behavior. Therefore, from the perspective of health factors, whether retired elderly people are willing and able to return to the labor market can not only provide theoretical evidence for the upcoming delayed retirement policy, but also alleviate the pressure of aging population on the economy and society. It can also provide policy suggestions for scientific and rational development of human resources for the elderly, improve their employment willingness, and improve their quality of life, which has very important theoretical value and practical significance.

\section{Literature review}

There have been sufficient studies on the relationship between healthy human capital and labor participation, most of which use subjective self-rated health as the explanatory variable to study the impact on labor supply, and believe that there is an obvious correlation between

\footnotetext{
a18113024@bjtu.edu.cn

b*17120547@bjtu.edu.cn
} 
the health status of the elderly population and labor participation. Bound et al. (2010) found that health status significantly affects workers' retirement decisions. Benjamin et al. (2003) used physical limitations as a tool variable for subjective self-assessment of health to study the impact of health on labor participation of elderly people in rural China, and found that there were significant differences among different genders, regions and work types. However, one of the disadvantages of self-assessment of health is the justification bias, that is, people deliberately devalue their health status after early retirement in order to show that they are not lazy people, thus leading to endogenous problems (Disney et al., 2006). A common approach to overcoming endogenous problems is to use objective health variables (such as length of hospital stay, BMI, parental health indicators, etc.) and health behaviors (current or former smokers, physical inactivity, alcohol abuse, etc.) as instrumental variables for subjective health variables (Cai and Kalb, 2006).

Other studies directly used objective health indicators to study the effects of labor participation. In some studies, mortality was used as a health indicator. Anderson and Burkhauser (1985) used panel data to study the differences in mortality in the middle and later stages of labor participation before the study. Since death was observed after the event, there was no endogeneity problem caused by justification bias or measurement error. In some other studies, indicators of body function limitation (ADL or IADL) were used (Kalwij and Vermeulen,2008). It was believed that indicators of body function limitation were less affected by economic and social factors faced by respondents, and there were less measurement bias. Part in addition to study the effect of specific diseases of labor participation, especially chronic disease, serious such as cancer, heart disease, stroke, lighter, such as high blood pressure, high cholesterol, diabetes, etc., the result shows that the onset of chronic diseases, reduce the elderly labor participation and the labor time, the effect increased with the severity of the disease. Harris (2010) used chronic diseases, such as diabetes and cardiovascular disease, to analyze the huge impact of their combined effects on labor market outcomes. In particular, for men, obesity, physical inactivity, hypertension, dyslipidemia, smoking and parental diabetes all had significant indirect effects on labor force participation.

Overall, most studies have found that the presence of health human capital of labor participation influence, but about health human capital for labor is involved in the positive influence or negative influence remains controversial, the elderly can drop because of health and reduce the labor involved in, or because of a lack of security will improve labor participation is unclear; At the same time, the lack of scientific test on the endogeneity of the quantitative model leads to bias in the estimation results. On the basis of existing research, this study used 2014 Chinese Longitudinal Healthy Longevity Survey (CLHLS) data, using self-reported health status indicators reflect the health status of the elderly, using Probit model to analyze the health human capital influence on the elderly labor participation in decision-making, and use Activities of Daily Living (ADL) as an objective health indicator to replace the self-assessment of health status to conduct a robustness test, and provides theoretical support for the formulation of policies for coping with the aging of the population and delayed retirement.

\section{Data and model}

By 2014 CLHLS data, the project was carried out in 1998 and then finished 2000, 2002, 2005, 2008, 2011, 2014, 6 times, such as sampling include Liaoning, Beijing, Shandong, Hunan, Sichuan, Guangdong and other 23 provinces, Survey sample of more than 7000 a year, basically represent the condition of China's elderly, health, the overall situation of social economic activities. This paper selects cross-sectional data from the latest survey in 2014 to study the impact of healthy human capital on labor participation of retired elderly people. The research object of this paper is the old people who have dropped out of the labor market according to the national retirement system. After screening, there are 1532 samples, among which 1225 urban samples and 307 rural samples are selected according to the urban and rural distribution. Considering China's mandatory retirement policy for most of the objects are urban residents, the sample and in line with the retirees features distribution, urban and rural areas to cities, there are a few in the rural residents enjoy retirement policy, such as rural teachers, town enterprise worker, the farm worker, etc. In order to the integrity of the samples, and facilitate comparison between urban and rural areas, retained the 307 rural samples.

The main explanatory variable of this paper is healthy human capital. Considering that the measurement error of healthy human capital and the connotation and denotation of measurement are controversial to some extent, this paper selects selfassessed health status as the indicator of healthy human capital to measure the retired elderly based on the existing empirical research. The explained variable is whether the elderly participate in paid market labor after retirement, excluding unpaid housework and other unpaid labor. The control variables mainly include three aspects: one is individual characteristic variables, including age, gender, education level and marital status; Second, family characteristics variables, including the number of family population, the number of children; Third, social characteristics variables, including urban and rural structure, annual household income and so on.

Table 1 Descriptive statistics

\begin{tabular}{|c|c|c|c|c|}
\hline Variable & Mean & $\begin{array}{l}\text { Standard } \\
\text { deviation }\end{array}$ & Max & Min \\
\hline $\begin{array}{c}\text { Labor } \\
\text { participation }\end{array}$ & $\begin{array}{l}0.183 \\
3\end{array}$ & 01945 & 1 & 0 \\
\hline $\begin{array}{l}\text { Self-reported } \\
\text { health }\end{array}$ & $\begin{array}{l}0.398 \\
6\end{array}$ & 0.3571 & 1 & 0 \\
\hline Age & 69.18 & 7.41 & 85 & 56 \\
\hline Male & $\begin{array}{l}0.626 \\
5\end{array}$ & 0.5015 & 1 & 0 \\
\hline
\end{tabular}




\begin{tabular}{|c|c|c|c|c|}
\hline $\begin{array}{l}\text { Years of } \\
\text { schooling }\end{array}$ & $\begin{array}{l}4.152 \\
9\end{array}$ & 2.8634 & 19 & 0 \\
\hline Married & $\begin{array}{l}0.607 \\
8\end{array}$ & 0.5125 & 1 & 0 \\
\hline $\begin{array}{l}\text { Household } \\
\text { size }\end{array}$ & $\begin{array}{l}1.843 \\
6\end{array}$ & 1.7127 & 6 & 0 \\
\hline $\begin{array}{l}\text { Number of } \\
\text { children }\end{array}$ & $\begin{array}{l}2.364 \\
2\end{array}$ & 1.4306 & 5 & 0 \\
\hline City & $\begin{array}{l}0.671 \\
2\end{array}$ & 0.3909 & 1 & 0 \\
\hline $\begin{array}{l}\text { Annual } \\
\text { income }\end{array}$ & $\begin{array}{l}5109 \\
8.48 \\
\end{array}$ & 32127.52 & $\begin{array}{l}100 \\
000 \\
\end{array}$ & 0 \\
\hline
\end{tabular}

Labor participation of the elderly is a binary variable, which has two values: participation in labor or not. In the case that the explained variable is a binary dummy variable, the discrete selection model is a relatively appropriate and often used empirical model, so this paper constructs the Probit binary selection model. In the study of the influence of healthy human capital on labor participation of the elderly, the influence of healthy human capital on labor participation of the elderly also has a negative effect on labor participation of the elderly, so the empirical model needs to consider the endogenous problem. In order to overcome the endogenous problems caused by missing variables and mutual causation, this paper uses the advantage of multi-period data to introduce the average self-assessed health status of individuals in the questionnaires in 2011 and 2014 as the measurement index of healthy human capital, so as to solve the endogenous problem in the empirical model.

Table 2 Probit Estimation of Self-Assessed Health Impact on Labor Participation

\begin{tabular}{|c|c|c|c|c|c|c|c|}
\hline Variables & All & Male & Female & City & Rural & Age $<70$ & Age $>70$ \\
\hline \multirow[t]{2}{*}{$\begin{array}{l}\text { Self-reported } \\
\text { health }\end{array}$} & $0.0568 * * *$ & $0.0663 * * *$ & $0.0508 * * *$ & $0.0449 * *$ & $0.0592 * * *$ & $0.0672 * * *$ & $0.0497 * *$ \\
\hline & $(0.0175)$ & $(0.0351)$ & $(0.0132)$ & $(0.0076)$ & $(0.0302)$ & $(0.0218)$ & $(0.0090)$ \\
\hline \multirow[t]{2}{*}{ Age } & $-1.257 * * *$ & $-1.001 * * *$ & $-1.299 * * *$ & $-1.353 * * *$ & $-1.353 * * *$ & 0.0000 & 0.0000 \\
\hline & $(0.0019)$ & $(0.0017)$ & $(0.0015)$ & $(0.0014)$ & $(0.0052)$ & (.) & (.) \\
\hline \multirow[t]{2}{*}{ Male } & $0.0404 * * *$ & 0.0000 & 0.0000 & $0.0262 * *$ & $0.0798 * * *$ & $0.0547 * * *$ & $0.0336 * * *$ \\
\hline & $(0.0245)$ & (.) & (.) & $(0.0271)$ & $(0.0661)$ & $(0.0397)$ & $(0.0311)$ \\
\hline \multirow[t]{2}{*}{$\begin{array}{l}\text { Years of } \\
\text { schooling }\end{array}$} & $0.0379 * *$ & $0.0335 * *$ & $0.0428^{*}$ & $0.0294 * * *$ & $0.0498 * *$ & $0.0252^{*}$ & 0.0426 \\
\hline & $(0.0112)$ & $(0.0126)$ & $(0.0162)$ & $(0.0122)$ & $(0.0242)$ & $(0.0130)$ & $(0.0115)$ \\
\hline \multirow[t]{2}{*}{ Married } & -0.0024 & $-0.0034^{*}$ & $-0.0324^{*}$ & -0.0131 & -0.0168 & $-0.0394 * *$ & -0.0091 \\
\hline & $(0.0245)$ & $(0.0301)$ & $(0.0322)$ & $(0.0235)$ & $(0.0449)$ & $(0.0498)$ & $(0.0255)$ \\
\hline \multirow[t]{2}{*}{ City } & $0.0228 * *$ & $0.0265^{* *}$ & 0.0218 & 0.0000 & 0.0000 & 0.0143 & $0.0156^{*}$ \\
\hline & $(0.0112)$ & $(0.0309)$ & $(0.0510)$ & (.) & (.) & $(0.0226)$ & $(0.0228)$ \\
\hline \multirow[t]{2}{*}{ Household size } & -0.0056 & -0.0048 & -0.0077 & 0.0059 & -0.0140 & -0.0170 & -0.0376 \\
\hline & $(0.0055)$ & $(0.0083)$ & $(0.0099)$ & $(0.0089)$ & $(0.0141)$ & $(0.0137)$ & $(0.0320)$ \\
\hline \multirow[t]{2}{*}{$\begin{array}{l}\text { Number of } \\
\text { children }\end{array}$} & 0.0055 & 0.0113 & 0.0069 & 0.0010 & 0.0148 & 0.0049 & 0.0036 \\
\hline & $(0.0057)$ & $(0.0070)$ & $(0.0093)$ & $(0.0056)$ & $(0.0117)$ & $(0.0183)$ & $(0.0076)$ \\
\hline \multirow[t]{2}{*}{ Annual income } & $-3.69 \mathrm{E}-07$ & $-7.40 \mathrm{E}-07$ & $-6.01 \mathrm{E}-07$ & $-1.23 \mathrm{E}-07$ & $-1.55 \mathrm{E}-07$ & $-4.99 \mathrm{E}-07$ & $-5.67 \mathrm{E}-07$ \\
\hline & (4.09E-07) & $(8.12 \mathrm{E}-07)$ & (7.05E-07) & $(1.55 \mathrm{E}-07)$ & (1.09E-07) & $(9.45 \mathrm{E}-07)$ & $(4.19 \mathrm{E}-07)$ \\
\hline $\mathrm{N}$ & 1532 & 1074 & 458 & 1225 & 307 & 439 & 1093 \\
\hline LR chi2 & 38.32 & 22.30 & 17.59 & 20.68 & 23.05 & 15.24 & 31.39 \\
\hline Prob $>$ chi 2 & 0.0035 & 0.0026 & 0.0438 & 0.0237 & 0.0082 & 0.0863 & 0.0017 \\
\hline Pseudo R ${ }^{2}$ & 0.0428 & 0.0512 & 0.0628 & 0.0291 & 0.0946 & 0.0694 & 0.0426 \\
\hline Log likehood & -296.87 & -368.27 & -129.21 & -247.23 & -128.32 & -125.15 & -263.63 \\
\hline
\end{tabular}

Notes: the estimated coefficient is the marginal effect; The Numbers in parentheses are standard error.

$*, * *$ and $* * *$ mean significant at the level of $10 \%, 5 \%$ and $1 \%$, respectively. 


\section{4 empirical analysis}

Firstly, the whole sample is estimated and analyzed. The results of Probit regression estimation show that healthy human capital has a significant impact on labor participation of the elderly in China. Older adults in good health had an average labor force participation rate of 5.68 percent higher than the control group. Moreover, it is significant at the level of $1 \%$, indicating that the better the health status of the elderly, the greater the possibility of labor participation. The higher the health level of the elderly after retirement, the higher the chance of obtaining jobs in the labor market and the higher the probability of returning to the labor market.

From the perspective of age grouping, the influence of healthy human capital on labor participation of the elderly in China is different in age. As the elderly age increases, their willingness to participate in labor is decreasing. The influence of healthy human capital on the labor participation of the elderly over 70 years old has decreased significantly compared with the younger elderly in the age group under 70 years old. Due to the limitation of age and condition, the influence of healthy human capital on labor participation of the elderly group is significantly reduced. In general, the marginal impact of healthy human capital on labor participation of young elderly is more significant, which indicates that the increase of healthy human capital is conducive to the improvement of labor participation willingness of young elderly who have quit or are about to quit the labor market, which also provides a thinking direction for the postponement of retirement age in China.

From the perspective of gender grouping, the effect of healthy human capital on labor participation of elderly men and elderly women is different, and the positive effect of healthy human capital on elderly men is greater than that on elderly women. Specifically, the participation rate of elderly men increased by 6.63 percent, while that of elderly women was only 5.08 percent. On the whole, healthy human capital has a more significant impact on the labor participation of elderly men in China. The labor income brought by healthy human capital of elderly men is higher than that of elderly women, and the investment in healthy human capital of elderly men is more profitable. It is not hard to see why, because the market value (income effect) of men's work is generally higher than that of women, as a result of men's comparative advantage in the labor market.

From the perspective of urban and rural grouping, the impact of healthy human capital on the labor participation of the elderly shows some differences between urban and rural areas, and the impact of healthy human capital on the labor participation of the elderly in rural areas is more significant. The health selfassessment index had a positive effect on the labor participation of the elderly in urban and rural areas at the level of $5 \%$, but the impact of healthy human capital on the labor participation of the elderly in rural areas was more significant. The probability of labor participation of the elderly in rural areas who rated themselves as healthy increased by $5.92 \%$, while the probability of labor participation of the elderly in urban areas only increased by $4.49 \%$.

\section{Robustness test}

Due to the subjectivity of self-assessed health status indicators to health measures, in order to ensure the reliability of the above analysis results, it is necessary to re-estimate the objective health status indicators. In this paper, ADL is used as an objective health indicator instead of self-assessed health status for robustness test. CLHLS survey on ADL includes bathing, dressing, going to the bathroom, indoor activities, controlling urine and feces, eating and other 6 items. In order to make a comprehensive comparison of the limited activities of daily living, we summed up the six restricted activities to get the daily activities, with values ranging from 0 to 6 , respectively indicating the number of activities that can be completed independently. The higher the value, the better the health status.

The estimated results of the impact of activities of daily living on labor participation decision-making show that the better the ADL is, the higher the labor participation rate is, no matter for the total sample or the subsamples divided by gender, age and urban and rural areas, indicating that there is a positive correlation between healthy human capital and labor participation.

Sum up the above empirical results, using subjective health measures and ADL, which are the indices of objectivity, get basically the same conclusion: the health human capital has significant positive influence on labor force participation of older people, health human capital, the better, the opportunity to work in the job market to obtain the higher, labor participation rate is higher.

\section{Conclusions}

Based on the data of CLHLS in 2014, this paper analyzed the impact of healthy human capital on the labor participation of the elderly in China, and conducted sub-sample regression by age, gender and urban and rural groups. Under the relevant theoretical framework, the Probit model of labor participation of the elderly was constructed. The results showed that after controlling for individual characteristic variables, family characteristic variables and social characteristic variables, health had a significant impact on labor participation of retired elderly people. With the decline of health status, labor participation rate of retired elderly people decreased significantly.

Taking into account the dual background of urban and rural areas in China and the health differences of age and gender of the elderly and their effects on labor participation of the elderly, this paper makes an empirical analysis of the samples by age, gender and urban and rural areas. In terms of age groups, health human capital for young old people under the age of 70 and over 70-year-old man has significant positive influence on labor force participation, but relatively 
speaking, more significant influence on the young man, and this gives us through healthy human capital in the process of mining working age population aging young old man's potential labor force participation provides a thinking direction; In terms of urban and rural groups, health human capital for the rural elderly labor participation in old people in cities and towns is relatively more significant, the influence of it to a certain extent, and the low level of rural elderly security, economic ability is weak, and not under the influence of rural elderly people in the traditional concept of "retirement", how to improve the rural elderly situation is also need to think about problems; In terms of sex, health human capital influence on older men and older women labor participation have certain differences, labor participation levels in older men than women, this is associated with the traditional social division of labor in our country, older women may do more housework and family care, this will affect their labor participation behavior, need further judge the rationality of the division of labor.

\section{Acknowledgment}

The author would like to thank Corresponding author- Chi Ying at Beijing Jiaotong University on the mentorship in research design and discussion.

\section{References}

1. Bound J, Stinebrickner T, Waidmann T. Health, economic resources and the work decisions of older men[J]. Journal of Econometrics, 2010, 156(1): 106129.

2. Cai L, Kalb G. Health status and labour force participation: evidence from Australia[J]. Health economics, 2006, 15(3): 241-261.

3. Disney R, Emmerson C, Wakefield M. Ill health and retirement in Britain: A panel data-based analysis[J]. Journal of health economics, 2006, 25(4): 621-649.

4. Harris A. Diabetes, cardiovascular disease and labour force participation in Australia: An endogenous multivariate probit analysis of clinical prevalence data[J]. Economic Record, 2009, 85(271): 472-484.

5. Kalwij A, Vermeulen F. Health and labour force participation of older people in Europe: what do objective health indicators add to the analysis? [J]. Health economics, 2008, 17(5): 619-638.

6. Kalwij A, Vermeulen F. Health and labour force participation of older people in Europe: what do objective health indicators add to the analysis? [J]. Health economics, 2008, 17(5): 619-638.

7. Novignon J, Nonvignon J, Arthur E. Health status and labour force participation in Sub - Saharan Africa: A dynamic panel data analysis[J]. African Development Review, 2015, 27(1): 14-26. 